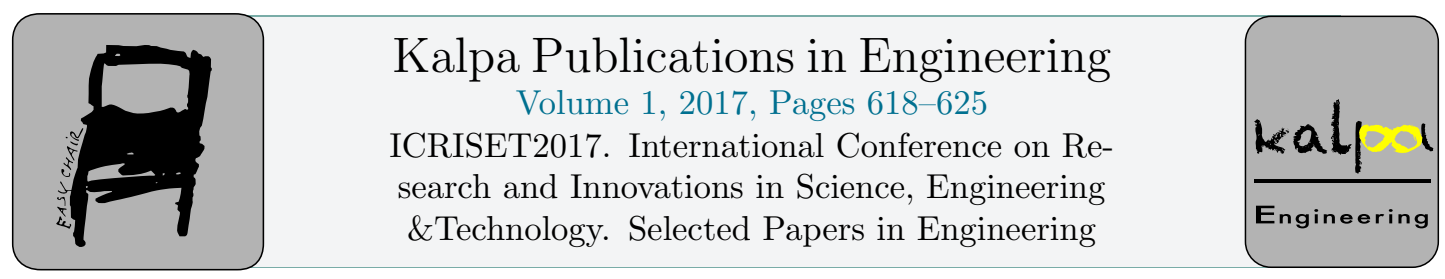

\title{
Design of Conical Roof Structure of Liquid Sulphur Storage Tank
}

\author{
Jay Naik $^{1}$, P.M.Agrawal ${ }^{2}$ and V.J. Patel ${ }^{3}$ \\ ${ }^{1}$ M.Tech student, Machine Design, BVM eng. College, v.v. nagar \\ ${ }^{2}$ Associated Professor, Mechanical Dept., BVM eng. College, v.v. nagar \\ 3Professor, Mechanical Dept., BVM eng. College, v.v. nagar \\ jsn.1411@live.com, pmagrawal@bvmengineering.ac.in, \\ vjpatel@bvmengineering.ac.in
}

\begin{abstract}
Design of Storage tank follows mainly three mechanical design of components namely (1) Roof Structure (2) Shell Design (3) Tank Foundation Bottom. This paper depicts design of conical roof structure under various loading conditions. Loading conditions are (1)Live load (2) Dead Load and (3) Thermal Load. Subjected to various constraints and releases.at last Result interpretation and future scope has been represented.
\end{abstract}

\section{Introduction}

Conical Roof Storage Roof tank is one of the oldest world technology or equipment and they are generally used over world in many petro-chemical facilities. Storage tanks are designed, fabricated and tested to code and standard. There are different types of codes and standards indicating similar common minimum additional requirements from company standards or specifications.

Engineer or tank designer who do the preliminary and detail design are normally not used to or not exposed to the actual site working methodology. Their designs are based on the code and standard requirements and basic theory from books and journals. Some would only rely on the Numerical and iterative software for the basic design, they have limited knowledge on the actual tank operation which restrict them on optimum cost and even safety detail design.

Apart from rules and procedures, fundamental depth of how the stresses behave in the tank material is essential for a complete safe design. Conical roof tanks are generally built in a big size and this would involve interdisciplinary approach for civil, chemical, mechanical, fire \& safety, construction, inspection, commissioning and operation 


\section{Literature review}

Storage tanks have been widely used in many processing industries particularly in the oil and refinery and petrochemical industry, which are to store an abundance of different product with crude oil as a major. Engineering Design of tank is difficult task and an optimum engineering of tank in planning phase of tank design is Cost effective. Estimating storage requirements for refinery is complex task. Tanks are expensive to build and maintain excess oil in storage never earns money. $\mathrm{H}$. $\mathrm{S}$ Berk in his paper presented conceptual design of tank and sizing Another aspect of conceptual design is the determination of maximum filling and withdrawal rates for nozzle and vent sizing[1]. Following Mr. H S Berk, Heydari Gorji and H kalat Jari explains Selection and sizing of Storage tanks. They have explained maximum design condition for conical roof tanks based on Design Pressure. In tabular form, they also explain task for tank selection based on flash point temperature and Diameter of tank [2].

Research on advancement of tank design and erection always relies on past failures of tanks. Some of case studies have also been studied in some papers.Luis A. Godoy in his case study explains Buckling of Fixed roof above ground oil storage tank under heat caused by external fire. This paper explains computational modelling and results of steel storage tanks under heat induced by an adjacent fire. In this research, modelling is limited to the structural behavior of the tank, giving importance on thermal buckling of the shell. Two tanks that buckled under a huge fire in Bayamon, Puerto Rico in 2009, are investigated in detail: a small tank with a self-supported conical roof, and a large tank having conical roof supported by a set of rafters and columns. For empty tank, the results indicate that a relatively low temperature is enough to produce static buckling of the shell. The buckling modes are compared with real deflection of tanks that were affected by fire [3].

Apart from Engineering Design of tank, Mechanical Design of Tank is equally important. Tank Shells design based on thin shell theory. In Standard API 650, explanation of 1)One Foot method and 2) VDM method is given in brief. But Explanation of Linear analysis using thin shell theory is not explained in details. Mr. Eyas Azzuni, Sukru Guzey work on this explanation gap by providing more focus on linear analysis using thin Shell theory. They compared the shell designs based on these three methods for different tank properties: height, diameter and allowable stress. For linear analysis, they have developed a stiffness-flexibility matrix method based on thin shell theory that gives the theoretical displacements and stresses at each shell course without any simplification or approximation. In a nutshell, shell designs using VDM may produce overstressed shell courses for some of the large steel liquid storage tanks when VDM is permissible to use. Linear analysis would give more accurate shell designs for those cases [4]

Buckling of shell is one of the major reason for fundamental mechanical design of Shell. Mr. David Bushell explains buckling of tank shell as a major pitfall for designers. In his work he explains buckling fundamentals with help of energy. The membrane stiffness is in general dominates over the bending stiffness. A thin shell can absorb a large amount of membrane strain energy with deforming negligible. It must deform much more in order to absorb an equivalent amount of bending strain energy. If the shell is loaded in such a way that most of its strain energy is in the form of membrane compression, and if there is a way that this stored-up membrane energy can be converted into bending energy, the shell may fail rather dramatically in a process called "Buckling" as it converts its bending energy to membrane energy. Very High deflections are generally required for conversion of membrane energy to bending energy. Occurrence of buckling depends on how the shell is loaded and on its material and geometrical properties. The prebuckling process is often nonlinear if there is a considerable large percentage of bending energy being stored in the shell throughout the loading history [5].

To overcome Pitfall of Buckled Shell many research work is going ahead.Mr.Jin Guang Teng throws light on recent trends and advances. This paper provides summery of recent advances and trends in the field of thin shell buckling. In his paper, the following topics are given importance: (a) 
imperfections in real structures and their influence; (b) buckling of shells under local/non-uniform loads and localized compressive stresses; and (c) the use of computational buckling analysis in the stability design of complex thin shell structures [6].

In seismic zone large tanks are usually subjected to seismic loading and sometimes cause over turning instability. Anumod A S explains FEM analysis of Tank subjected to Seismic loading. The objective of his paper is to study the effect of various components of earthquake on sloshing response of liquid storage tanks. First, commonly used theory for unidirectional analysis of liquid behavior in cylindrical tanks was reviewed. Second, the Finite Element Modelling (FEM) method which was used to simulate dynamic response of the liquid tank system was explained. The FEM was validated using a set of analytical calculation, which is used in available design guidelines. Third, a parametric study for some vertical, cylindrical ground supported tanks with different aspect ratios excited by various time series of earthquake accelerations was performed [7].

Catastrophic failure due to internal corrosion is explained by W.Geary as a case study in his paper. Catastrophic failure of a $10 \mathrm{~m}$ high, $8 \mathrm{~m}$ diameter steel storage tank containing approximately $350 \mathrm{~m} 3$ of waste solvent led to a significant environmental incident in 2009. An investigation was carried out to establish the root cause and to learn lessons that might prevent a reoccurrence [8].

Designing of tank is followed by on sight erection and commissioning of tank. There are two methods to erect tanks under API 650 involves the assembly of the tank from the bottom to top with the use of scaffolds (the traditional method). The second method assembles the tank from the top to bottom using a hydraulic jack system (the jacking method) Argentina-based tank builder Cantoni Gruas has suggested third way for building the tank in one paper [9].

\section{Standards for design}

\subsection{Tank Design standards}

Design of tank widely follows API 650 for welded tank design. Section 5 of API 650 provides guidelines for roof structure and Shell Design.

\subsection{Roof Structure Design}

Roof Structure Design accurately assumed as a Space truss design. For Rafter supported Roof Structure, Numerical analysis of Structure has been analyzed based on AISC ASD design criteria. Roof Structure Design has 3 important parameters for measurement of structural check (1) Deflection (2) Bending Stress (3) Utility ratio.

\section{Roof structure design}

Roof structure design directly follows tank design data subjected to application. following table contains design data provided by designing consultancy.

Table 1:Design data

\begin{tabular}{|l|c|}
\hline Type of Tank & $\begin{array}{c}\text { Column Supported Cone Roof } \\
\text { Tank }\end{array}$ \\
\hline Service & \begin{tabular}{c} 
Liquid Sulphur Storage tank \\
\hline Flash Point
\end{tabular} \\
\hline Tank Inside Diameter & $42 \mathrm{~m}$ \\
\hline
\end{tabular}




\begin{tabular}{|l|c|}
\hline Tank Height & $9 \mathrm{~m}$ \\
\hline Design Pressure & 0 bar(guage $)$ \\
\hline Design Temperature & $178^{\circ} \mathrm{C}$ \\
\hline MDMT & $5^{\circ} \mathrm{C}$ \\
\hline Roof Slope & $1: 16$ \\
\hline Material property & SA36 $\left(\sigma_{\mathrm{y}}=250 \mathrm{Mpa}, \mathrm{E}=199000\right.$ \\
& $\mathrm{Mpa})$ \\
\hline CTE & $1.2 \times 10^{-5} /{ }^{\circ} \mathrm{C}$ \\
\hline
\end{tabular}

\subsection{Roof Structure Data:-}

Roof structure is Rafter supported and consist of 1 centered column and 8 other supported columns. Roof consist of first order rafter, second order rafter. Roof connection for rafters are lateral braces and girder connection for internal connection between two rafters. Constraints and releases are given at rafter ends and columns subjected to application. Design is checked based on allowable stress design criteria (AISC-ASD).

Major design parameters for roof Structure are:

1. Deflection ratio

2. Bending stress

3. Utility ratio

\subsection{Numerical Analysis}

Numerical analysis of roof structure has been done in STAAD Pro. Software analysis has been done in several stages as Follows:

1) Geometry and modelling of a structure according to drawing.

2) Material property for each members and connections are defined.

3) Loading condition and constraints are given appropriately on structure.

4) Design code (ASD) for Bending Stress, deflection and utility ratio.

5) Run analysis

6) Post processing

7) Result check

8) Result interpretation

\subsection{Assumptions}

1. Material of structure is homogeneous and isotropic.

2. Considering rotational symmetry of roof structure geometry, only $1 / 8^{\text {th }}$ portion of roof structure has been taken for analysis and design.

3. For simplicity of design each members of roof structure has been taken as standard geometry and material as given in software pre-defined data book.

4. At Roof to shell connection supports are considered as roller support for finding maximum reactions and deflections. 


\subsection{Material Property}

As per the requirement of buyers for international project here european beam members has been taken for structural design.

\begin{tabular}{|l|l|l|l|}
\hline $\begin{array}{c}\text { Member } \\
\text { Specification }\end{array}$ & Standard section & Standard & Section Property \\
\hline $1^{\text {st }}$ Order Rafter & IPE330 & European & I Section $/ \mathrm{H}=330 \mathrm{~mm}$ \\
\hline $2^{\text {nd }}$ Order Rafter & IPE270 & European & I Section $/ \mathrm{H}=270 \mathrm{~mm}$ \\
\hline Girder & HE300B & European & I Section $/ \mathrm{H}=300 \mathrm{~mm}$ \\
\hline Lateral Braces & L $80 \times 80 \times 10$ & European & L Section $/ \mathrm{H}=\mathrm{B}=80 \mathrm{~mm}$ \\
\hline Columns & PIPE & European & Circular section \\
\hline
\end{tabular}

\section{Loading conditions and constraints}

\subsection{Constraints}

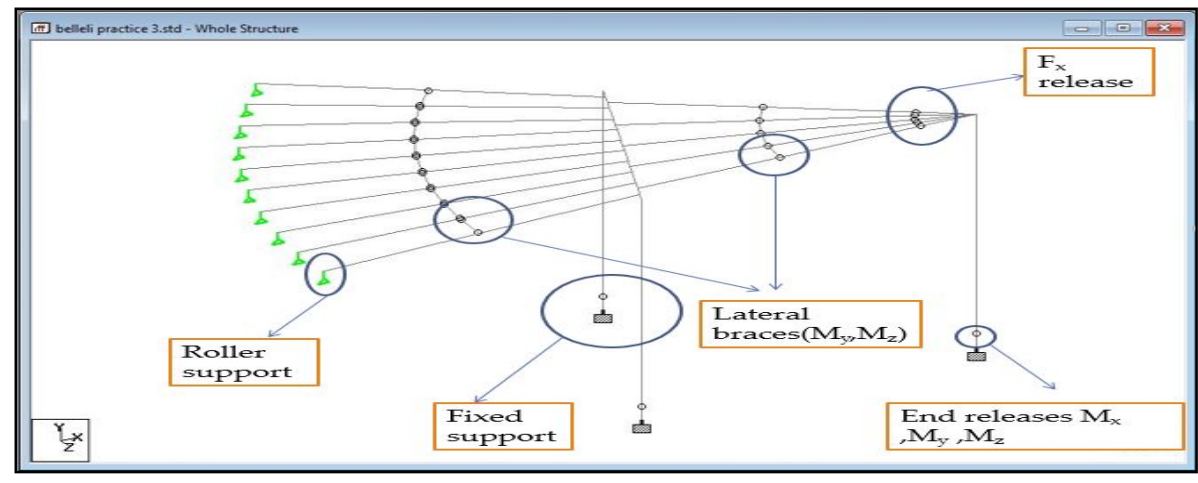

Figure 1: Constraints of degrees of freedoms and Releases

\subsection{Calculation of load distribution}

Because of long span length of rafters, to avoid sagging of rafter members lateral braces are used to provide intermediate supports. Because of this both $1^{\text {st }}$ and $2^{\text {nd }}$ order rafter further classified as Headers.

Here all headers have loading conditions as follows:

1. Live load(Trapezoidal distribution)

2. Dead load(Trapezoidal distribution)

3. Thermal load 


\section{Analysis and Post Processing Result}

\subsection{Analysis}

1. Analysis of Structure with Load combination has been run without any error.

2. Results shows no component failure under load combinations.

3. Post processing provides many results to interpret the structure critical conditions.

4. For simplicity of interpretation main three parameters has been checked.

Which are as follows:

1) Deflection

2) Bending stress

3) Utility ratio

\subsection{Deflection}

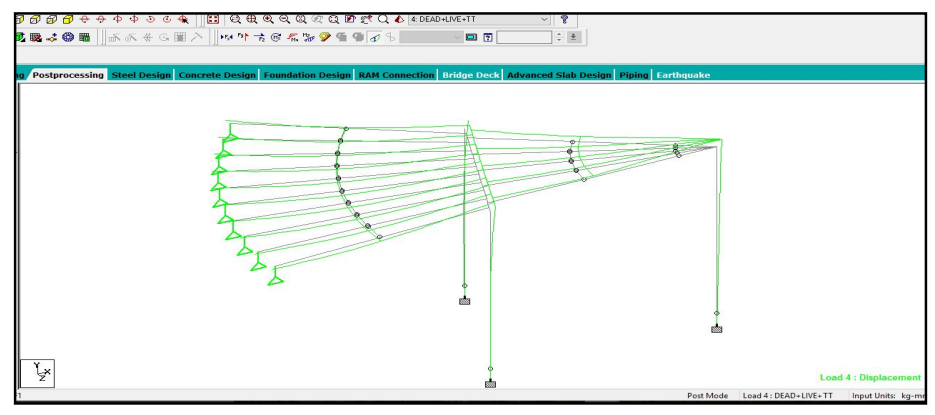

Figure 2: Deflection of Roof Structure element

1. As shown in Figure above deflection will follow same in all rafters.

2. Central rafter members are subjected to comparative more deflection.

3. Column Node Connection will show positive deflection in Y direction.

\section{Bending Stress}

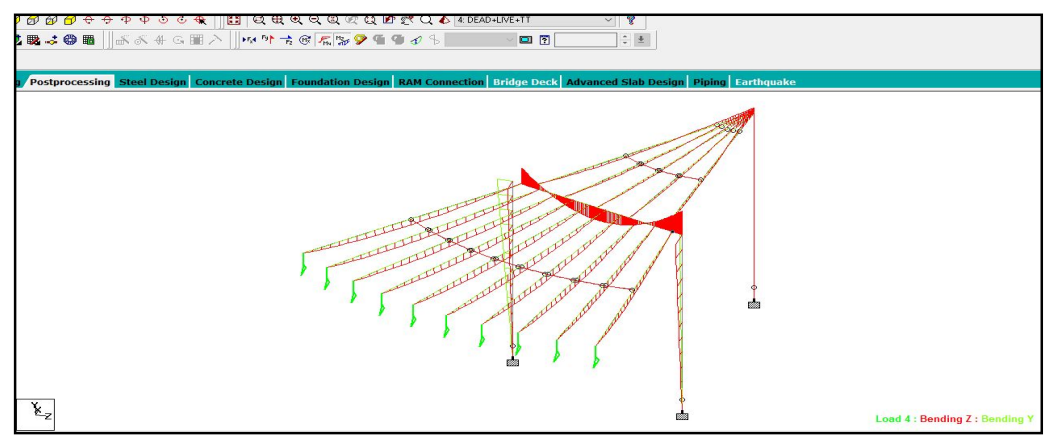

Figure 3 : Bending Stress pattern 
1. As shown in figure, bending moment will be comparatively high in central rafter members and Girder central members.

2. Resulting Bending moment will directly affect the Bending Stress, which concludes similarity of Bending Stress Pattern with Bending Moment.

3. All Bending Stress Values are within Material Strength Limit and indicates safe Design subjected to loading combinations.

\section{Utility Ratio}

Utility ratio is ratio of actual Stress Ratio to allowable stress ratio. Hence, it should be less than 1. As following figures depicts utility ratio remains less than 1 .

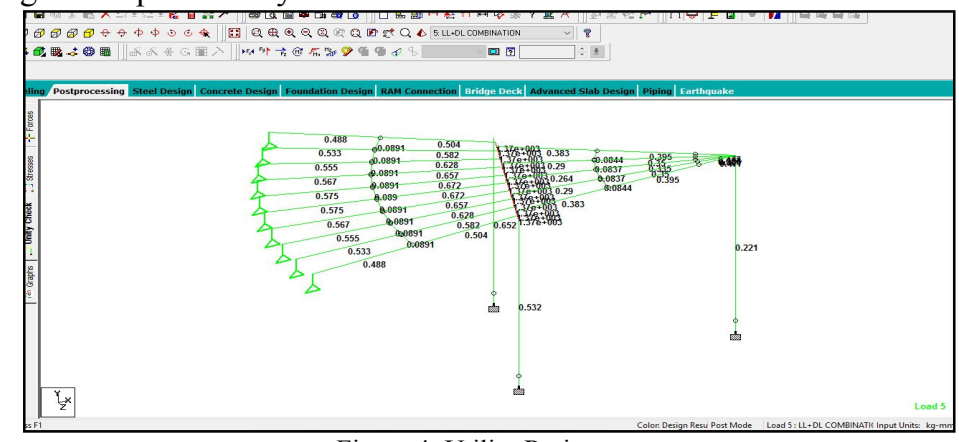

Figure 4: Utility Ratio

\section{Conclusion}

1. Deflection criteria $\mathrm{L} / 400$ has been taken for the longest span and is coming under the limiting value.

2. Maximum bending stress values are $80 \mathrm{~N} / \mathrm{mm}^{2}$ both in tension and compression.

3. Centred members which are longest in length are deflecting more compare to other members.

4. At column supported node deflection in $\mathrm{Y}$ direction is more compare to other intermediate points.

5. At supported column node thermal load is dominating over live load and dead load that is why some nodes are showing positive deflection in higher magnitude.

6. Maximum deflection value is $24.26 \mathrm{~mm}$ approximately.

7. reaction is maximum in middle span Reactions at centred column is a maximum, for the roller support.

\section{Bibiliography}

[1] H.S.Berk, "Conceptual Design Of Tankage," Chemical Engineering, 1981.

[2] A. G. a. H. Jari, "Improve selection and sizing of storage tank,"Hydrocarbon Processing,2006.

[3] L. A. G. a. J. C. Mendez-Degró, "Buckling of aboveground storage tanks with conical roof," Department Of Civil Engineering,University of Puerto Rico, Mayagüez.

[4] S. G. Eyas Azzuni, "Comparison of the shell design methods for cylindrical liquid storage tanks 2015.

[5] D. Bushnell, "Buckling of Shells—Pitfall forDesigners," AIAA, 1981. 
[6] J. G. Teng, "Buckling of thin shells: Recent advances and trends," Department of'Civil and Structural Engineering, Hong Kong Polytechnic University, 1996.

[7] A. A.S, "Finite Element Analysis of Steel Storage Tank Under Siesmic Load," International Journal ofEngineering Research and Applications,2014.

[8] J. H. W. Geary *, "Catastrophic failure of a carbon steelstorage tank due to internal corrosion," Case Studies in Engineering Failure Analysis, 2013.

[9] C. Gruas, "Third way to Build a tank," 2013. 